\title{
Comparative analysis of pathogenicity, phylogenetic relationship and host fungal rice blast pathogen Magnaporthe grisea
}

\begin{abstract}
Magnaporthe grisea is the most devastating pathogen of rice in all over the world, and the principal model organism for elucidating the molecular source of fungal disease of plants. This study, we report the draft sequence of the M. grisea genome. Examination of the gene set facilitates an insight into the adaptations essential by a fungus to source disease. The genome encodes a huge and varied set of secreted proteins, with those defined by remarkable carbohydrate-binding domains. This fungus also possesses a prolonged family of G-protein-coupled receptors, numerous novel virulence-associated genes and huge suites of enzymes occupied in secondary metabolism. Consistent with a function in fungal pathogenesis, the expression of a number of these genes up regulated during the early stages of infection-related development. The $M$. grisea genome has been subject to invasion and proliferation of active transposable elements, reflecting the colonel nature of this fungus imposed by widespread rice cultivation. The study will be helpful to describe phylogenetic relations, pathogenicity, and genome analysis, drug design against diseases caused by fungi and cDNA synthesis and amplification to desired targets.
\end{abstract}

Keywords: M. grisea; cDNA; Genome; G-protein; Pathogenicity; Phylogenetic
Volume 5 Issue 5 - 2017

\author{
Saleem Ahmad, ${ }^{1,2}$ Abdul Raqeeb, ${ }^{3}$ Muhammad \\ Qasim ${ }^{4}$ \\ 'Key Laboratory of Pathogenic Fungi and Mycotoxins of Fujian \\ Province, Fujian Agriculture and Forestry University, China \\ ${ }^{2}$ Key Laboratory of Biopesticide and Chemical Biology of \\ Education Ministry, and School of Life Science, Fujian Agriculture \\ and Forestry University, China \\ ${ }^{3}$ Department of Forestry and Range Management,Arid \\ Agriculture University, Pakistan \\ ${ }^{4}$ Key laboratory of Insect Ecology, College of Plant protection, \\ Pakistan
}

Correspondence: Saleem Ahmad, Key Laboratory of Pathogenic Fungi and Mycotoxins of Fujian Province, Fujian Agriculture and Forestry University, China,

Email saleem.chilas@yahoo.com

Received: July 29, 2017 | Published: November 21, 2017

\section{Introduction}

Magnaporthe grisea, also identified as rice blast fungus, rotten rice neck, rice seedling blight, oval leaf spot of graminea, blast of rice, ${ }^{1}$ pitting disease, ryegrass blast, and Johnson spot is a plantpathogenic fungus that causes a serious disease affecting rice. ${ }^{2}$ Rice blast, caused by Magnaporthe grisea, is considered the most important disease of rice worldwide 3 because of its extensive distribution and destructiveness under favorable conditions. Infection of rice plants occurs from airborne conidia, and symptoms appear as lesions or spots. ${ }^{4}$ This disease remains the single major threat to the rice industry. Even though disease modeling research has shown that the pathogen could initiate multiple disease cycles if introduced, the exact behavior of the disease will not be known until it occurs. The stages of development, Rice blast is a polycyclic disease depending on favorable conditions. ${ }^{5}$ The pathogen survives winter as conidia or mycelium on diseased rice stubble, seed or in alive plants. ${ }^{6}$

Although M. grisea can overwinter on cereals and weed host, the role of these hosts in the disease cycle remains subject to controversy. ${ }^{7}$ Primary inoculums (conidia) are thought to originate from overwintered rice straw mainly. The Wind, water carry conidia and infect rice plants after landing on them. A few days later, conidiophores are produced and release new airborne spores (conidia) ${ }^{8}$ The function of these hosts in the rice blast disease cycle remains subject to controversy. ${ }^{7}$ This controversy mainly described by the genetic diversity of the fungus, the hosts and the variation in experimental conditions. Research verified that although $M$. grisea can infect a broad range of plant hosts, some strains are very species, and even cultivar, specific, ${ }^{9}$ described a new species for the strains of Magnoporthe from Oryza sativa, Eragrostriscurvula, Eleusinecoracana, Loliumperenne and Setaria spp. According to these authors, the accurate name of the isolates associated with these plants is $M$. oryzae where M. grisea should use for the isolates associated with Digitaria spp. Worldwide, rice blast occurs in all rice-growing regions. Although rice blast has recorded in the Northern Territory. ${ }^{10}$ The disease isolated from weeds in several locations of New South Wales (M. Priest personal communication). None of these locations were within, or near, the rice growing area of NSW. It is currently unknown if the isolates present in NSW are pathogenic to rice. Rice is the staple food crop for a huge part of the human population in the worldwide. ${ }^{11}$ Rice blast is by far the mainly important disease of rice. It originates wherever rice is grown-up, it is for all time important, and it is all the time threat. Failures of entire rice crops have resulted in a straight line from rice blast epidemics. Rice blast has not at all eliminated from the area in which rice is grownup and a single modify in the way in which rice grown or in the way resistance genes deploy can outcome in significant disease victims still after years of successful management. ${ }^{12} \mathrm{M}$. grisea is the majority destructive pathogen of rice and the principal model for elucidating the molecular source of fungal disease of plants. ${ }^{13}$ The filamentous fungus M. oryzae causes rice blast, the most serious disease of cultivated rice. Cellular differentiation of $M$. orzyae forms an infection structure called appressorium, which generates enormous cellular turgor that is adequate to rupture the plant cuticle. ${ }^{14}$ The relationship of trehalose metabolism to fungal virulence explored in the rice blast fungus $M$. grisea. To decide the role of trehalose synthesis in pathogenesis. ${ }^{15}$

Although we have a growing knowledge of the core elements of the signaling pathways that regulate plant infection processes in many pathogens, our knowledge of what lies up and downstream is fragmentary at best. One efficient approach to further characterize genes regulated by these pathways is to identify the downstream transcription factors. General factors essential for transcription of every one gene, participate in the formation of the transcription- 
initiation complex near a start site. However, transcription factors may exhibit a specific combinatorial distribution in different cell types that help to direct determination (choice of cell fate) and differentiation (synthesis of recognized cell-specific proteins). Characteristic features include $\mathrm{Zn}$ finger domains, homeodomains, b-zip (basic leucine zipper), helix-loop-helix (HLH), to name but a few. Certain domains such as homeodomains also associated with protein-protein interactions. Others such as HLH form homo or heterodimers while binding DNA. Two novel DNA binding domains are found extensively in fungi; IPR001138 is a Cys-rich domain that requires. ${ }^{16} \mathrm{Zn}$ for binding and IRP007219 is found commonly in genes regulating metabolism and development. ${ }^{16}$ Gene expression profiling based on DNA/oligo microarrays has proven to be extremely valuable in elucidating expression profiles of suites of genes and generating lengthy lists of genes putatively involved in determining phenotype or cellular activities. ${ }^{17}$ However, DNA microarray expression profiling experiments do not reveal the specific DNA targets of these pathways following a transcription factor activation. An approach termed ChIP-chip allows for the comprehensive identification of targets of transcription factors. ${ }^{18}$

\section{Microarray analysis}

Microarray-based transcriptome analysis during the infection related morphogenesis in Magnaporthe grisea aim: Identification of genes/factors required for pathogenicity and invasive growth as potential new targets for plant protectants. ${ }^{19}$

\section{Model organism}

Magnaporthe grisea is the fundamental agent of rice blast disease, as a model organism to learn plant-pathogen relations and infectionrelated morphogenesis at a biochemical and molecular level. ${ }^{20} \mathrm{M}$. grisea is a filamentous ascomycete, and it causes probably the most severe disease on cultivated rice. ${ }^{21}$ Besides its economic importance, this fungus is a suitable model pathogen because it can grow in culture, it genetically well characterized, and an efficient transformation system has established.

\section{Morphological methods}

Formal recognition based on mutually direct examination of the symptom on rice plants and straight examination of the characteristic spores (conidia) created by the fungus (M. grisea). ${ }^{22}$

\section{Inducing sporulation on rice tissue}

Samples showing classic symptoms need to placed in a moist chamber to increase sporulation. Greer and Webster ${ }^{23}$ productively induced sporulation on mutually panicle neck nodes and leaves by insertion the samples on "three pieces of humid filter paper in glass Petri dish and incubated for 48 hours under constant fluorescent light at room temperature".

\section{Inducing sporulation on media}

M. grisea is simply isolated from Potato Dextrose Agar (full or half strength). Guochang \& Shuyuan ${ }^{24}$ reported that cornmeal, oatmeal agar, rice straw agar, and cornmeal agar induced very high-quality to good sporulation. ${ }^{25}$

\section{Conclusion}

The objectives are to assess the genotype, and pathotype diversity of $M$. grisea populations analyzed the relationship between genotype lineages and blast pathos types and Identify sites suitable for resistance screening. The methodology to used to include Sample collection and its identification, isolation /culture techniques. Morphological methods are; records of sample collected works information, inducing sporulation on media, rice tissue, and possible sources of confusion with other diseases.

\section{Acknowledgements}

None.

\section{Conflict of interest}

The author declares no conflict of interest.

\section{References}

1. Meena B. Morphological and molecular variability of rice blast pathogen pyricularia grisea (cooke) sacc. UAS, Dharwad, India; 2006. 87 p.

2. Wilson RA, Talbot NJ. Under pressure: investigating the biology of plant infection by Magnaporthe oryzae. Nat Rev Microbiol. 2009;7(3):185.

3. Dean RA, Talbot NJ, Ebbole DJ, et al. The genome sequence of the rice blast fungus Magnaporthe grisea. Nature. 2005;434(7036):980-986.

4. Lanoiselet V, Cother E, Ash G. CLIMEX and DYMEX simulations of the potential occurrence of rice blast disease in south-eastern Australia. Australasian Plant Pathology. 2002;31(1):1-7.

5. Skamnioti P, Gurr SJ. Against the grain:safeguarding rice from rice blast disease. Trends in biotechnology. 2009;27(3):141-150.

6. Nyvall RF. Diseases of Rice, in Field Crop Diseases Handbook. USA: Springer; 1989. p. 385-425.

7. Borromeo E, Nelson RJ, Bonman JM, et al. Genetic differentiation among isolates of Pyricularia infecting rice and weed hosts. phytopathology. 1993;83:393-393.

8. Sutton JC, Swantonnd CJ, Gillespie T. Relation of weather variables and host factors to incidence of airborne spores of Botrytis squamosa. Canadian Journal of Botany. 1978;56(20):2460-2469.

9. Pak D, Ming PY, Vincent L, et al. Reservoir of cultivated rice pathogens in wild rice in Australia. European Journal of Plant Pathology. 2017;147(2):295-311.

10. Aldrick SJ, Buddenhagen I, Reddy A. The occurrence of bacterial leaf blight in wild and cultivated rice in Northern Australia. Australian Journal of Agricultural Research. 1973;24(2):219-227.

11. Tilman D, Cassman KG, Matson PA, et al. Agricultural sustainability and intensive production practices. Nature. 2002;418(6898):671.

12. TeBeest DC, Guerber, Ditmore M. The Plant Health Instructor. PHI-I-2007-0313-07. 2007.

13. Parker D, Beckmann M, Enot DP, et al. Rice blast infection of Brachypodium distachyon as a model system to study dynamic host/ pathogen interactions. Nature Protocols. 2008;3(3):435.

14. Duan Z, Chen Y, Huang W, et al. Linkage of autophagy to fungal development, lipid storage and virulence in Metarhizium robertsii. Autophagy. 2013;9(4):538-549.

15. Foster AJ, Jenkinson JM, Talbot NJ. Trehalose synthesis and metabolism are required at different stages of plant infection by Magnaporthe grisea. The EMBO Journal. 2003;22(2):225-235.

16. Mitchell TK, Ralph AD, Jin-Rong X, et al. Protein chips and chromatin immunoprecipitation-emerging technologies to study macromolecule interactions in M. grisea. Advances in Genetics, Genomics and Control of Rice Blast Disease. 2009:73-82. 
17. Frias-Lopez J, Shi Y, Tyson GW, et al. Microbial community gene expression in ocean surface waters. Proceedings of the National Academy of Sciences. 2008;105(10):3805-3810.

18. Buck MJ, Lieb JD. ChIP-chip: considerations for the design, analysis, and application of genome-wide chromatin immunoprecipitation experiments. Genomics. 2004;83(3):349-360.

19. Felitti S, Shields K, Ramsperger M, et al. Transcriptome analysis of Neotyphodium and Epichloë grass endophytes. Fungal Genetics and Biology. 2006;43(7):465-475.

20. Caracuel-Rios Z, Talbot NJ. Talbot, Cellular differentiation and hos invasion by the rice blast fungus Magnaporthe grisea. Curr Opin Microbiol. 2007;10(4):339-345.

21. Egan MJ, Wang ZY, Jones MA, et al. Generation of reactive oxygen species by fungal NADPH oxidases is required for rice blast disease. Proceedings of the National Academy of Sciences. 2007;104(28):1177211777
22. Kim S, Park SY, Kim KS, et al. Homeobox transcription factors are required for conidiation and appressorium development in the rice blast fungus Magnaporthe oryzae. PLoS genetics. 2009;5(12):e1000757.

23. Greer C, Webster R. Occurrence, distribution, epidemiology, cultivar reaction, and management of rice blast disease in California. Plant Disease. 2001;85(10):1096-1102.

24. Guochang S, Shuyuan S. Conditions for Sporulation and Preservation of Conidia of Rice Blast Fungus Pyricularia Grisea, in Major Fungal Diseases of Rice. USA: Springer; 2001. p. 111-117.

25. kiran kumar A. Studies on brown leaf spot disease (helminthosporium spp.) of finger millet and foxtail millet. India: University of agricultural sciences gkvk; 2011. 